\title{
Total content of phenols and antioxidant activity of grape skins and seeds cabernet sauvignon cultivated in Valle de Guadalupe, Baja California, México
}

\author{
L. Castro-López ${ }^{\text {a }, ~ G . ~ C a s t i l l o-S a ́ n c h e z, ~ L . ~ D i ́ a z-R u b i o, ~ a n d ~ I . ~ C o ́ r d o v a-G u e r r e r o ~}$ \\ Escuela de Enología y Gastronomía, Universidad Autónoma de Baja California, Carretera Transpeninsular Ensenada-Tijuana 3917, \\ Colonia Playitas C.P. 22860 Ensenada, Baja California, México
}

\begin{abstract}
The evaluation of the antioxidant capacity of grape cultivars Cabernet sauvignon is important because it varies according to the production area. In this work, it was evaluated the content of phenolic compounds and the total antioxidant capacity (CAT) of grape skins and grape seed Cabernet sauvignon (Vitis vinifera L.) in three vineyards located in the Valley of Guadalupe, B.C, México. The content of total phenols was determined by the Folin-Ciocalteau method and the CAT of grape skin and seed extracts by the stabilization methods of the $\left(\mathrm{ABTS}^{\bullet+}\right)$ and $\mathrm{DPPH}^{\bullet}$ radicals. The CAT in the seed extracts was increased $(P<0.05)$ in the following order: vineyard $2<$ vineyard $1<$ vineyard 3 . The highest contents of gallic acid, resveratrol and rutin were found in the extracts that presented the highest CAT, which corresponded to the cultivars of vineyard 3. The same happened in extract of skins, having vineyard 3 the contents of CAT $\left(\mathrm{ABTS}^{\bullet+}\right.$ ) higher. The total phenolic seed compound was presented in vineyard 2 with 1,545, followed by vineyard 1 with 1,523, vineyard 3 with 1,146 expressed as g GAE.100 $\mathrm{g}$ of sample. In skin, the behavior was as follows; vineyard 3 <vineyard $2<$ vineyard 1. 1,062, 1,086, 1,115 expressed as g GAE.100 g sample respectively.
\end{abstract}

Keywords: antioxidant, phenolics, ABTS, gallic acid.

\section{Introduction}

Grape (Vitis vinifera L.) is a major fruit crop in the world with many cultivars varying in characteristics, such as flavor and colour, with or without seeds, which are associated to the content of phenolic compounds and consequently with antioxidant capacity. Grapes are one of the major sources of phenolic compounds, as compared with other fruits and vegetables (Mulero et al., 2015) [1]. Phenolic compounds are an integral part of the human diet and are considered to benon-nutrients with biologically active compounds (Subramani et al., 2002; Mulero et al., 2015) [2] and they constitute one of the most numerous and widely distributed groups of natural products in the plant kingdom. They play a very important role in the composition of grapes and wines, contributing to principal sensory properties, such as colour, astringency and bitterness (Puértolas et al., 2010) [3]. These compounds were identified and quantified in several fruits and vegetables, and show a high correlation with antioxidant activity (Soares, 2002 [4]; Einbond et al., 2004) [5]. Polyphenols are classified into two main groups: non-flavonoids (hydroxybenzoic and hydroxycinnamic acids and their derivatives, stilbenes and phenolic alcohols) and flavonoids (anthocyanins, flavanols, flavonols and dihydroflavonols) (Fanzone et al., 2012) [6]. Biological properties of polyphenols are attributed to their powerful

\footnotetext{
a e-mail: castro.liliana1@uabc.edu.mx
}

antioxidant, metal chelating and antiradical activities (Šeruga et al., 2011) [7]. Also, phenolic compounds reduce the risk of chronic diseases, eliminating free radicals that induce vascular relaxation, and they exhibit anti- inflammatory, anti-cancer, antiviral and antibacterial properties (Gris et al., 2011) [8].

\section{Materials and methods}

\subsection{Plant material}

The grapes used were Cabernet sauvignon year 2017 from three winemakers located in the Guadalupe Valley, México.

\section{Extracts preparation}

The frozen grapes were peeled and separated into skins and seeds, during this process the plant material was kept at $-12{ }^{\circ} \mathrm{C}$ and covered with light. The extracts were generated by a methanolic maceration, which was kept under stirring for 24 hours, then filtered and the solvent was removed under reduced pressure.

\section{Determination of antioxidant capacity}

\subsection{Free Radical Reduction: DPPH Assay}

Antioxidant activity was determined according to the method reported by Garza et al. (2011) [9]. Solutions 
of each compound in ethanol were serially diluted with additional ethanol to concentrations in the range of 125 to $0.5 \mu \mathrm{g} / \mathrm{mL}$. The DPPH solution was prepared at a concentration of $125 \mu \mathrm{M}$. Each diluted compound or blank $(500 \mu \mathrm{L})$ was placed individually in a test tube, and $0.5 \mathrm{~mL}$ of DPPH was added. The solutions were stirred and allowed to react in the dark for $30 \mathrm{~min}$. Spectrophotometric measurement was performed at a wavelength of $517 \mathrm{~nm}$. The reduction of DPPH was calculated from the following equation (Salazar, et al., 2015) [10]:

$$
\% \text { Reduction }=[(\text { Blank }- \text { Sample }) / \text { Blank }] \times 100
$$

We created a linear regression curve with the percent reduction as a function of the concentration of each compound and calculated the concentration that effectively reduced $\mathrm{DPPH}$ by $50 \%\left(\mathrm{EC}_{50}\right)$. All experiments were performed in triplicate, and the mean and standard deviation were calculated in each case.

\section{ABTS assay}

According to the methodology developed by Re et al. [11] and described by Kuskoski et al. 2005 [12] the radical $\mathrm{ABTS}^{\bullet+}$ is obtained after the reaction of ABTS $(7 \mathrm{mM})$ with potassium persulfate $(2.45 \mathrm{mM}$, final concentration) incubated at room temperature $\left( \pm 25^{\circ} \mathrm{C}\right)$ and in the dark for $16 \mathrm{~h}$. Once the radical $\mathrm{ABTS}^{\bullet+}$ is formed, it is diluted with ethanol until an absorbance value between 0.70 $( \pm 0.1)$ and $754 \mathrm{~nm}$ (wavelength of maximum absorption) is obtained. The filtered samples (anthocyanins) are diluted with ethanol until an inhibition of 20 to $80 \%$ occurs, compared to the absorbance of the blank, after adding $20 \mu \mathrm{L}$ of the sample. To $980 \mu \mathrm{L}$ of dilution of the $\mathrm{ABTS}^{\bullet+}$ radical thus generated, the A754 is determined at $30^{\circ} \mathrm{C}, 20 \mu \mathrm{L}$ of the sample (anthocyanin dilution) is added and the A754 is measured again after 1 minute. The absorbance is measured continuously after 7 minutes. The synthetic antioxidant of reference, Trolox, is tested at a concentration of $0-15 \mu \mathrm{M}$ (final concentration) in ethanol, under the same conditions, which is also done with ascorbic acid (0-20 mg/100 mL). The results are expressed in TEAC (antioxidant activity equivalent to Trolox) and in VCEAC (antioxidant activity equivalent to vitamin $\mathrm{C}$ ), in the latter case because it is food.

\section{6. $\beta$-carotene assay}

Heat-induced oxidation of an aqueous emulsion system of â-carotene and linoleic acid was used as the antioxidant activity test model. One milliliter of $\beta$-carotene $(0.2 \mathrm{mg} / \mathrm{mL})$ dissolved in chloroform was added to an Erlenmeyer flask containing linoleic acid $(0.02 \mathrm{~mL})$ and Tween $20(0.2 \mathrm{~mL})$. The mixture was than dosed with $0.2 \mathrm{~mL}$ of the corresponding flavonoid or standard solution in methanol at a concentration of 10-3 M. Fifty milliliters of distilled water, saturated for $15 \mathrm{~min}$ with oxygen, was added to the flask. The resulting mixture was shaken and kept for $2 \mathrm{~h}$ at $50^{\circ} \mathrm{C}$. The absorbance of the samples was measured on a Hewlett-Packard 8453 spectrometer at $470 \mathrm{~nm}$, immediately after their preparation $(t) 0 \mathrm{~min}$ ) and at the end of the experiment ( $t$ ) $120 \mathrm{~min}$ ). Antioxidant activity was calculated as percent inhibition of oxidation
Table 1. Total polyphenolic compounds content in grape seeds extract and skin (Vitis vinifera L.) of the variety Cabernet Sauvignon.

\begin{tabular}{lll}
\hline $\begin{array}{l}\text { Cabernet } \\
\text { Sauvignon }\end{array}$ & \multicolumn{2}{l}{ Total polyphenolics } \\
(g GAE.100 g of sample)
\end{tabular}

versus control sample without flavonoid added, using the equation:

$(\%$ antioxidant activity $) 100 \times[1-($ As $0-$ As 120$) /$ (Ac 0 - Ac 120)]

where As 0 is the absorbance of sample at $0 \mathrm{~min}$, As 120 is the absorbance of sample at $120 \mathrm{~min}$, Ac 0 is the absorbance of control sample at $0 \mathrm{~min}$, and Ac 120 is the absorbance of control sample at $120 \mathrm{~min}$ (Burda and Oleszek, 2001) [13].

\section{Total polyphenol content}

To determine the total phenolic content (TPC) by the FolinCiocalteu method, $1 \mathrm{mg}$ of each extract or fraction in $1 \mathrm{~mL}$ of methanol, was prepared. Briefly, the extract solution $(100 \mu \mathrm{L})$ was diluted to $3 \mathrm{~mL}$ with distilled water and then oxidized with the Folin-Ciocalteu reagent $(500 \mu \mathrm{L})$; after $3 \mathrm{~min}$, the reaction was neutralized with $\mathrm{Na}_{2} \mathrm{CO}_{3}$ $20 \%$ solution $(2 \mathrm{~mL})$ and then allowed to react for $60 \mathrm{~min}$ in darkness. The absorbance of the resulting bluecolored reaction was measured at $650 \mathrm{~nm}$ in a Beckman DU7500 spectrophotometer. The calibration curve was performed with gallic acid (concentration range $0.30-9.00 \mu \mathrm{g} / \mathrm{mL}$ ) and the results were expressed as $\mathrm{mg}$ of gallic acid equivalents per $g$ of dry extract. Data are reported as mean \pm SD for three replicates (Perez et al., 2016) [14].

\section{Results and discussion}

The good amount of extractable polyphenols, present in the samples compared to the values of other fruits and vegetables, may be very related to their antioxidant capacity, because these types of polyphenols are the ones that can be extracted more easily (Saura-Calixto et al., 2009) [15]. These results can be verified by the studies carried out by Pinelo et al. (2005) [16], where they indicate that the grape seeds contain polyphenols, representing a high content of tannic compounds, which alone represent $30 \%$ of the total phenolic compounds (Fuhrman and Aviram, 2001) [17].

The total concentrations polyphenolics compounds was higher in all seed extracts than the skin samples. Reaching the maximum concentration of polyphenols 1,545 (g GAE.100 $\mathrm{g}$ of sample) the extract of seed of the winemaker 2. As we can see in Table 1. Another research work indicates that the concentrations of polyphenols in seed are higher than in peel, and most are tannins (Flancy, 2000) [18]. Tannins are abundant in pips, 
Table 2. Flavonoids compound content in grape seeds extracts and skin (Vitis vinifera) of the variety Cabernet Sauvignon.

\begin{tabular}{lcl}
\hline & \multicolumn{2}{c}{ Flavonoids (g EQ.100 g of sample) } \\
\hline V1-Seeds & $1.004 \pm 0.015$ & $(7)$ \\
V2-Seeds & $0.821 \pm 0.038$ & $(8)$ \\
V3-Seeds & $0.349 \pm 0.007$ & $(9)$ \\
V1- Skin & $12.747 \pm 0.243$ & $(10)$ \\
V2- Skin & $7.490 \pm 0.147$ & $(11)$ \\
V3- Skin & $16.861 \pm 0.010$ & $(12)$ \\
\hline
\end{tabular}

Cabernet Sauvignon

Table 3. Antioxidant activity for Cabernet Sauvignon.

\begin{tabular}{cll}
\hline & DPPH** & ABTS \\
\hline V1-Seeds & $0.0167 \pm 0.0003$ & $0.312 \pm 0.035(13)$ \\
V2-Seeds & $0.0133 \pm 0.0026$ & $0.048 \pm 0.006(14)$ \\
V3-Seeds & $0.0306 \pm 0.0034$ & $0.504 \pm 0.002(15)$ \\
V1- Skin & $0.1463 \pm 0.0031$ & $0.899 \pm 0.008(16)$ \\
V2- Skin & $0.0586 \pm 0.0038$ & $0.842 \pm 0.008(17)$ \\
V3- Skin & $0.1216 \pm 0.0032$ & $1.308 \pm 0.004(18)$ \\
\hline CE$_{50}$ : average effective concentration $\mathrm{mg} / \mathrm{mL}$.
\end{tabular}

because they have between 50 and $90 \%$ of the total proanthocyanidins (Flancy, 2000) [18].

According to Kennedy et al. (2000) [19], the function of phenols in seed is related to the dormancy stage and its viability, since the content of phenols makes the seed permeable to water making germination possible.

At the same time, it can be said that hydrolyzable tannins are in small amounts compared to the extractable and condensed tannins.

According to Furhman et al. (2001) [17] the content of antioxidants in grapes is directly related to the content of different polyphenols. The contents of polyphenolic material vary considerably according to the type of wine one has, of the grape, variety, environmental factors and winemaking techniques (Frankel et al., 1995) [20]. In the skins, the antiradical effect is greater in the red varieties. According to Flancy (2000) [18], the concentrations of anthocyanins, flavonols and total tannins constitute, in quantity, the highest percentage of the phenolic content present in said structures.

Bartolomé et al. (2004) [21] found values of antioxidant capacity in extract of dry grape skins between $3.2-11.1 \mathrm{mg} / \mathrm{mL}$ DPPH, being these values influenced by the variety, stage of development and harvest year of the grape, and presenting values much lower than those found in the present work, so that the samples of the varieties studied here represent a greater anti-radical power.

\section{Conclusion}

Extensive research suggests that grape seed extract is beneficial in many areas of health because of its antioxidant effect to bond with collagen, promoting youthful skin, cell health, elasticity, and flexibility. This results show that despite the possibility of the transfer of polyphenolics from the grape skin to the wine during the winemaking process and the possible loss of some of these compounds by oxidation during the air-drying process, the seed and skin byproducts are still good sources of antioxidant compounds suitable for use as dietary supplements.

LCL and GC acknowledge support from Programa para el Desarrollo Profesional Docente, para el Tipo Superior (PRODEP).

\section{References}

[1] J. Mulero, G. Martínez, J. Oliva, S. Cermeño, J.M. Cayuela, P. Zafrilla, A. Martínez-Cachá, A. Barba, Food Chem. 180, 25 (2015)

[2] S. Subramani, C.A. Casimir, G. Krewer, J. Agric. Food Chem. 50, 2432 (2002)

[3] E. Puértolas, G. Saldaña, S. Condón, I. Álvarez, J. Raso, J. Food Chem. 119, 1063 (2010)

[4] S.E. Soares, Rev. Nutrição. 15, 71 (2002)

[5] L.S. Einbond, K.A. Reynertson, X.D. Luo, M.J. Basile

[6] M.F. Fanzone, V. Zamora, M. Jofré, C. Gómez Cordovés, A. Peña-Neira, J. Sci. Food Agric. 92, 704 (2012)

[7] M. Šeruga, I. Novak, L. Jakobek, Food Chem. 124, $1208(2011)$

[8] E.F. Gris, F. Mattivi, E.A. Ferreira, U. Vrhovsek, D.W. Filho, R.C. Pedrosa, J. Agric. Food Chem. 59, 7954 (2011)

[9] A. Garza-Juárez, M.L. de la Salazar-Cavazos, R. Salazar-Aranda, J. Pérez-Meseguer, N.W. de Torres, Planta Med. 77, 958 (2011)

[10] A.R. Salazar, G.G. Granados, M.J. Pérez, G.M. González, T.N. Waksman, Molecules 20, 17903 (2015)

[11] R. Re, N. Pellegrini, A. Proteggente, A. Pannala, M. Yang, C. Rice-Evans, Free Radical Bio. Med. 26, 1231 (1999)

[12] E.M. Kuskoski, A.G. Asuero, A.M. Troncoso, F.J. Mancini, R. Fett, Food Sci. Technol. 25, 726 (2005)

[13] S. Burda, W.J. Oleszek, Agric. Food Chem. 49, 2774 (2001)

[14] C. Pérez-Meseguer, C. Delgado-Montemayor, T. Ortíz-Torres, R. Salazar-Aranda, P. CorderoPérez, N.W. De Torres, Pak. J. Pharm. Sci. 29, 343 (2016)

[15] F. Saura-Calixto, I. Crit. Rev. Food Sci. Nutr. 49, 145 (2009)

[16] M. Pinelo, M. Rubilar, M. Jerez, J. Sineiro, M.J. Núñez, J. Agric. Food Chem. 53, 2111 (2005)

[17] B. Fuhrman, M. Aviram, Curr. Opin. Lipidol. 12, 41 (2001)

[18] C. Flancy, Madrid: Editorial Mundi-Prensa. 783 (2000)

[19] J. Kennedy, G. Troup, J. Pilbrow, D. Hutton, D. Hewitt, C. Hunter, G. Jones, G. Aust, J. Grape Wine R 6, 244 (2000)

[20] E. Frankel, A. Waterhouse, P. Teissedre, J. Agric. Food Chem. 43, 890 (1995)

[21] B. Bartolomé, V. Nuñez, M. Monagas, C. GómezCordovés, Eur. Food Res. Technol. 218, 173 (2004) 